\title{
Effect of Ovariectomy on the Hypothalamic Content of Immunoreactive Gonadotropin-Releasing Hormone in the Female Mouse as Revealed by Quantitative Immunocytochemistry and Radioimmunoassay
}

\author{
KAREN P. BRISKI, BURTON L. BAKER, AND A. KENT CHRISTENSEN \\ Department of Anatomy and Cell Biology and the Reproductive Endocrinol- \\ ogy Program, The University of Michigan Medical School, Ann Arbor, \\ Michigan 48109
}

\begin{abstract}
Our radioimmunoassay data reveal that ovariectomy for either one or two months resulted in a significant decrease in the GnRH content of the mouse basal hypothalamus, while in mice ovariectomized for two weeks the $\mathrm{GnRH}$ levels did not differ significantly from controls. Parallel immunocytochemical analyses gave similar results. Tissue sections from specific regions of the median eminence in intact and ovariectomized mice were immunolabeled for $\mathrm{GnRH}$ with the peroxidase-antiperoxidase procedure of Sternberger. Differences in area and average unit density of the reaction product were measured with a Quantimet 720 image analyzer. At two weeks after ovariectomy, a majority of matched sections from intact and ovariectomized animals, taken in each sampled region of the median eminence, showed no visually apparent difference in $\mathrm{GnRH}$ immunoreactivity. Quantitative image analysis of these preparations revealed no statistically significant difference in either the area of neural tissue covered by deposit or the average unit density of this material in any given region. In contrast, in mice ovariectomized for either one or two months, immunolabeled GnRH was decreased throughout the cephalo-caudal extent of the median eminence. In each region, a reduction in reaction deposit was observed over most of the area in which $\mathrm{GnRH}$ is localized, especially in the medial aspects of this distribution. Image analysis of these preparations revealed a significant reduction of both specimen area immunolabeled for $\mathrm{GnRH}$ and the average unit density of reaction product in each region of the median eminence. While the decrease in density was uniform throughout the median eminence, the greatest reduction in area covered by deposit occurred in the infundibular region.

The demonstration of a decrease in basal hypothalamic $\mathrm{GnRH}$ in the chronically ovariectomized mouse suggests that $\mathrm{GnRH}$ neurosecretion is increased in response to the absence of the ovaries and supports the premise that tonic secretion of this neurohormone, in the mouse, may be subject to regulation by the gonads. At two weeks after ovariectomy, it is possible that changes in $\mathrm{GnRH}$ secretion occur without a concomitant alteration in hypothalamic hormone content. In addition, the quantitative immunocytochemical data suggest that $\mathrm{GnRH}$ neurons responsive to ovariectomy terminate throughout the rostro-caudal extent of the mouse median eminence, especially in the medial sites of localization. A proportionally greater number of these endings appear to be present within the infundibular region of the median eminence, relative to the other regions sampled.
\end{abstract}

It is well established that pituitary gonadotropin secretion is maintained by a trophic neurohormone, gonadotropin-releasing hormone $(\mathrm{GnRH})$, secreted by the endocrine hypothalamus. There is growing evidence that
K.P. Briski is now with the Neuroendocine Research Laboratory, Department of Physiology, Michigan State University, East Lansing, MI 48814.

Address reprint requests to Dr. Karen P. Briski, Department of Anatomy and Cell Biology, Medical Science II Building. The University of Michigan Medical School, Ann Arbor, MI 48109. Received May 18, 1982. Accepted September 13, 1982 
in some species gonadal steroid hormones may act at a neural site to suppress this hypophysiotropic signal. In the rat, withdrawal of these steroids by gonadectomy results in an increase in GnRH neurosecretion, as indicated by an increase in hypothalamic GnRH biosynthesis (Moguilevsky et al., 1975; Reichlin, 1976) and an elevation in the release of this neurohormone into the portal plasma (Ben-Jonathan et al., 1973; Eskay et al., 1977; Sherwood and Fink, 1980). In addition, several investigators, using radioimmunoassay (RIA) techniques, have described a gonadectomy-induced decrease in the GnRH content of hypothalamic extracts from rats (Araki et al., 1975; Shin and Howitt, 1976; Wheaton and McCann, 1976; Chen et al., 1977; Badger et al., 1978; Kobayashi et al., 1978) and sheep (Wheaton, 1979); while immunocytochemical (ICC) analyses have revealed a decrease in demonstrable hormone within axon terminals in the median eminence of the gonadectomized rat (Campbell and Ramaley, 1978; Kobayashi et al., 1978; Gross, 1980), mouse (Briski, 1979; Gross, 1980), and sheep (Polkowska and Jutisz, 1979). Both RIA and ICC studies have shown that replacement therapy with gonadal steroids results in a return of hypothalamic GnRH levels to control values (Shin and Howitt, 1976; Chen et al., 1977; Kobayashi et al., 1978; Gross, 1980).

Since immunocytochemistry can identify GnRH-containing neurons in situ by specific labeling of intracellular hormone, this technique can be used to demonstrate the terminal distribution of $\mathrm{GnRH}$ neurons that undergo a decrease in hormone content in response to gonadectomy. Of the few such analyses performed to date, some have been limited to only one region of the rat median eminence (Campbell and Ramaley, 1978; Kobayashi et al., 1978). More recent studies, however, have reported a decrease in immunocytochemically demonstrable $\mathrm{GnRH}$ throughout the cephalo-caudal extent of this structure in both the rat (Gross, 1980) and mouse (Briski, 1979; Gross, 1980). In all of these previous studies, differences in immunostaining for $\mathrm{GnRH}$ were assessed only by visual comparison of the immunolabeled preparations.

In the early phases of the present study, a slight normal variation in both the amount and distribution of labeled hormone was observed from animal to animal, with the result that visual comparisons of immunocytochemical reaction products sometimes involved subtle decisions that were not partic- ularly evident to less experienced microscopists. In order to get away from this somewhat subjective aspect of immunocytochemical analysis, we have utilized quantitative image analysis of the immunocytochemical preparations, yielding results which are more objective and which are susceptible to statistical verification. We have also utilized parallel measurements by RIA to ascertain the effect of our experimental manipulations on basal hypothalamic GnRH stores. We feel that these quantitative approaches should provide more reliable information than has previously been available on changes in hypothalamic GnRH after ovariectomy in the female mouse.

\section{MATERIALS AND METHODS Animals}

Young adult female mice (Swiss CB-1 strain, Charles River), ranging in weight from 50 to $60 \mathrm{gm}$, were housed under a lighting schedule of $14 \mathrm{hr}$ of light and $10 \mathrm{hr}$ of darkness, and received food and water ad libitum. After a two-week period of acclimation, the animals were divided into two groups: Those in one group were designated as unoperated controls; animals in the other group were anesthetized with metofane and ovariectomized by the dorsal approach. At this point, both groups were transferred to specially designed cages (Baker and Briski, unpublished) featuring a perforated metal divider. A male mouse was placed on one side, while a group of 3-5 female mice was housed on the other side. The purpose of this housing arrangement was to ensure maximal synchrony of estrous cycles among the intact females (Whitten, 1966; Whitten and Champlin, 1973). Vaginal smears were taken daily from the intact animals.

At least six pairs of ovariectomized animals and intact controls of comparable age were sacrificed by decapitation between 0800 and 1000 hours at each of three time points after surgery: two weeks, one month, and two months. The majority of the control animals were killed during the morning of proestrus, after having completed two consecutive four-day cycles, while the remainder were sacrificed throughout the cycle. No significant difference was noted in the results obtained from these two control groups.

\section{Tissue Processing, Sampling, and Immunocytochemical Procedures}

Hypothalami were processed for light microscopic immunocytochemistry according to the following procedure. After decapitation, 
the basal hypothalamus was rapidly exposed and flooded with Bouin's fixative, elevated from the base of the skull by lateral props and allowed to fix in situ by immersion of the whole head in Bouin's fixative. After 12 $\mathrm{hr}$, a tissue block comprising the whole hypothalamus and preoptic area was dissected out and returned to fresh fixative for an additional $24 \mathrm{hr}$. The blocks were than dehy. drated in graded alcohols, cleared in carbon disulfide, and embedded under vacuum in Paraplast. Serial $4-\mu \mathrm{m}$ coronal sections were cut from each block and mounted on albumin-coated slides. Every twentieth section was stained with cresyl violet to serve as a guide in the selection of appropriate sections for immunocytochemistry.

For each pair of ovariectomized and intact control animals, comparable sections from three specific regions of the median eminence were matched and simultaneously immunostained for $\mathrm{GnRH}$, under identical conditions, using the peroxidase-antiperoxidase procedure of Sternberger et al. (1970). The three regions chosen for analysis were: the mid region, where the infundibular recess of the third ventricle is the widest; the infundibular region, where the infundibular stalk separates from the base of the brain; and the caudal or post-infundibular median eminence.

Paraffin sections were rehydrated in descending concentrations of alcohols and rinsed in distilled water. Prior to the successive application of each immunoreagent, sections were washed with $0.9 \% \mathrm{NaCl}$ buffered to $\mathrm{pH} 7.6$ with $0.05 \mathrm{M}$ Tris buffer (TBS), the diluent for all immunoreagents, and subsequently incubated for $5 \mathrm{~min}$ with normal goat serum (Cappel), 1:30, in TBS, to diminish nonspecific binding. The detection of $\mathrm{GnRH}$ antigenic sites was achieved by incubation of sections with Dermody's rabbit anti-GnRH antiserum \#154, preabsorbed with mouse liver powder, at a dilution of 1:300 (gift of Parke-Davis to B. L. Baker). Bound primary antibody was labeled indirectly with peroxidase enzyme by successive incubations with goat anti-rabbit IgG (Cappel), 1:10, and peroxidase-anti peroxidase complex (PAP), 1:50 (gift of L. A. Sternberger to B. L. Baker). Each of the three immunoreagents was applied to sections for $30 \mathrm{~min}$ at room temper. ature in a moisture chamber. Peroxidase activity was visualized by means of enzy. matic reduction of $0.001 \% \mathrm{H}_{2} \mathrm{O}_{2}$, in the presence of $0.05 \mathrm{M} 3,3^{\prime}$-diaminobenzidene (DAB, Sigma), free base, in TBS at $\mathrm{pH} 8.0$, at $4^{\circ} \mathrm{C}$. Reacted sections were subsequently treated with $2 \%$ aqueous osmium tetroxide (Baker) at room temperature to render oxidized $\mathrm{DAB}$ complexes insoluble. Although the sections were not counterstained, the procedure described above left a slight tan coloration in the sections.

The specificity of the Dermody \#154 antiserum for GnRH has been characterized by Gross (1976) in this laboratory, using staining conditions similar to those utilized here. These immunoabsorption tests showed that immunolabeling in the mouse hypothalamus could be eliminated by preabsorption of $\# 154$ at a dilution of $1: 300$, with 16.9 pmols of synthetic GnRH. In addition, the following additional specificity controls were carried out: 1) substitution of normal rabbit serum for the primary antiserum; 2) systematic elimination of each of the immunoreagents; and 3) deletion of DAB, the marker for $\mathrm{GnRH}$. No non-specific labeling was revealed by these controls.

\section{Quantification of the Immunocytochemical Product}

In the present study, a Quantimet $720 \mathrm{im}$ age analyzer (Cambridge/IMANCO, Monsey, NY) was used to provide a quantitative estimate of differences in immunolabeling for $\mathrm{GnRH}$ in matched control and experimental tissue. Measurements of both 1) the total specimen area covered by reaction deposit and 2) the average unit density of this material were used as a means of comparing the amount of immunocytochemical reaction product generated by the paired sections under identical conditions.

Upon projection onto the Quantimet's picture screen, a specimen image was automatically divided into standard unit areas, or pixels, each corresponding to $0.73 \mu \mathrm{m}^{2}$ on the specimen (occasionally, smaller pixels were used, ranging to $0.46 \mu \mathrm{m}^{2}$ ). According to the literature, axons and axon terminals within the external lamina of the rat median eminence, the site where GnRH has been localized, have diameters of $0.1-0.5 \mu \mathrm{m}$ and $0.3-$ $1.4 \mu \mathrm{m}$, respectively (Monroe, 1967). Thus, the pixels used in the present study were roughly the same size on the specimen as the axons and axon terminals containing $\mathrm{GnRH}$ activity. The Quantimet possesses the capability to assign to each pixel a value for optical density, according to a graded internal scale of 64 shades of gray between black and white. Since the optical density of the immunolabeled areas of the specimen was greater than that of the unstained neural tissue, it was possible to choose a threshold 
value to permit detection of only those areas of the specimen covered by reaction deposit. By this means, the Quantimet, in conjunction with a computer program, was able to assess for each immunolabeled preparation the number and individual unit density values of the pixels containing DAB. From these measurements, it was possible to determine for each specimen the total area covered by reaction deposit and the average unit density of this material.

Paired experimental and control tissue from each region of the median eminence were analyzed by the Quantimet. Data for total immunocytochemical reaction area covered by deposit and average density from each sampled region were analyzed with Student's T test for paired observations. Changes in these parameters were compared between sampled regions using Student's T test for means.

\section{Radioimmunoassay}

Ovariectomized and proestrus control animals used for radioimmunoassay were killed between 0800 and 1000 hours at either two weeks, one month, or two months after surgery. After decapitation, a tissue block comprising the basal hypothalamus was excised from the brain and immediately frozen on dry ice. The approximate boundaries of the block were as follows: Rostral, through the retrochiasmatic area, posterior to the optic chiasm; lateral, along the hypothalamic sulci; dorsal, two-thirds of the height of the hypothalamus; and caudal, anterior to the mammillary bodies. According to current information, immunoreactive $\mathrm{GnRH}$ within the mouse basal hypothalamus appears to be present exclusively within axons and axon terminals; GnRH-specific antisera have consistently revealed intra-axonal $\mathrm{GnRH}$ activity within this area of the brain, but have failed to identify GnRH-containing perikarya within this region.

After rapid freezing, the tissue blocks were stored at $-20^{\circ} \mathrm{C}$ until extraction the following day, which was performed according to the method of Snabes et al. (1977). Hypothalamic tissue was homogenized in $2 \mathrm{~N}$ acetic acid at $4{ }^{\circ} \mathrm{C}$ and centrifuged for $30 \mathrm{~min}$ at $1000 \mathrm{~g}$; the supernatant was neutralized with $2 \mathrm{~N} \mathrm{NaOH}$ and diluted to a final volume of $1 \mathrm{ml}$ with $0.01 \mathrm{M}$ gel-PBS, pH 7.0. Extracts were returned to storage at $-20^{\circ} \mathrm{C}$ until analysis for $\mathrm{GnRH}$ content. Radioimmunoassay for GnRH was carried out according to the procedure described by Snabes et al. (1977). The antiserum used, Niswender's R42, was kindly provided by Dr. T. M. Nett (Colorado State University) and was employed at a dilution of $1: 200,000$ in normal rabbit serum diluted 1:300 in EDTA-PBS, pH 7.0. Samples were analyzed in duplicate, at two dilutions. Sample aliquots and the synthetic GnRH standard, P 113 (Parke-Davis), were diluted to 500 $\mu \mathrm{l}$ with $0.01 \mathrm{M}$ gel-PBS, $\mathrm{pH}$ 7.0. To each tube was added $100 \mu \mathrm{l}$ of ${ }^{125} \mathrm{I}-\mathrm{GnRH}$ (approximately $1000 \mathrm{cpm}$ ) and $200 \mu \mathrm{l}$ of anti-GnRH at the dilution described above. After incubation for $24 \mathrm{hr}$ at $4^{\circ} \mathrm{C}, 200 \mu \mathrm{l}$ of sheep antirabbit IgG, 1:15, was added and the incubation allowed to continue for an additional 72 $\mathrm{hr}$ at $4^{\circ} \mathrm{C}$. At this time, the precipitates were washed with $3 \mathrm{ml}$ of cold $0.01 \mathrm{M}$ gel-PBS, $\mathrm{pH}$ 7.0 , and then counted. Data were expressed as ng GnRH per mouse medial-basal hypothalamus and were analyzed for significance with the Student's t test for means.

\section{RESULTS Intact Controls}

The immunochemical localization of $\mathrm{GnRH}$ in the median eminence of intact female mice appeared essentially as has been described by Gross (1976) and will only be summarized here. In the mid-region of the median eminence (Fig. 1), immunocytochemically demonstrable $\mathrm{GnRH}$ is organized predominantly into a bilateral tract, the medial aspect of which is particularly dense and lies in close proximity to the apices of the tubero-infundibular sulci. Laterally, the tract is closely apposed to the entire lateral border of each sulcus. Immunoreactive hormone is also present in a relatively diffuse distribution between the sulci and the infundibular recess of the third eminence. Small, variable deposits of reaction product are present in close proximity to the ependymal lining of the lateral and ventral walls of the infundibular recess. These individual sites are also found within both laminae of the central expanse of the median eminence.

More caudally, in the infundibular or junctional region, most of the GnRH immunoreactivity is also organized into a bilateral tract, the lateral aspect of which extends transversely, dorsal to the entire length of each sulcus (Fig. 2). Although the activity is heaviest medially, at the apex of the sulcus, it can also be demonstrated in a more diffuse distribution extending between the apices of the sulci, beneath the third ventricle. In ad- 
dition, a variable amount of $\mathrm{GnRH}$ activity is also dispersed within the infundibular stalk.

In the post-infundibular or caudal median eminence, demonstrable GnRH is observed within two bilateral tracts which extend in a transverse direction on either side of the midline. At the midline, more diffuse hormone activity extends from the base of the brain to the ependymal lining of the third ventricle.

\section{Two Weeks After Ovariectomy}

Visual comparison of the paired immunostained sections, control and experimental, from each sampled region showed no apparent difference in either distribution or density of $\mathrm{GnRH}$ labeling between the majority of the ovariectomized animals and their intact controls. A representative pair of matched sections, with the experimental on the left and the control on the right, is shown for each sampled region: Mid-median eminence (Figs. 3, 4), infundibular region (Figs. 5, 6), and caudal median eminence (Figs. 7,8 ). However, occasional pairs of sections from each region showed either an increase or decrease in the ovaricctomized animals compared to the controls.

Quantitative analysis of these preparations confirmed the visual impression that there was no ovariectomy-induced change in immunocytochemical reaction product two weeks after the operation. The data from image analysis (Fig. 9) revealed no significant change in either the area of neural tissue covered by reaction deposit or the average unit density of this material in any sampled region of the median eminence in ovariectomized mice.

\section{One Month After Ovariectomy}

At one month after surgery, there was a readily apparent decrease in immunolabeled $\mathrm{GnRH}$ in the median eminence of all of the ovariectomized animals. In each animal, this response could be observed throughout the cephalo-caudal extent of this structure, including the mid-median eminence (Figs. 10, 11), the infundibular region (Figs. 12, 13), and the caudal median eminence (Figs. 14, 15). Throughout the median eminence, ovariectomy resulted in a marked reduction in immunoreactivity associated with the prominent tubero-infundibular tract. This decrease was particularly obvious in the medial portion of the tract, at the apex of the tuberoinfundibular sulcus. In contrast, immuno- reactive hormone in lateral areas of the tract was variably affected by ovariectomy, with some pairs of sections showing no visible difference in immunoreactivity. Further, in each sampled region there was also a marked decrease in $\mathrm{GnRH}$ immunoreactivity within more diffusely organized loci, particularly medial to the sulci in the mid- and infundibular regions, and within the locus of activity extending from the ventricular ependyma to the base of the brain in the caudal median eminence.

Image analysis of the immunolabeled preparations (Fig. 16) demonstrated a statistically significant decrease in total specimen area covered by immunocytochemical reaction product in each region of the median eminence one month after ovariectomy. The magnitude of this response was not constant throughout the median eminence: the greatest decrease in area occurred in the infundibular region, while the other two regions showed lower values that were similar to each other in magnitude. Ovariectomy after one month also resulted in a decrease in the average density of immunostaining for $\mathrm{GnRH}$, which was uniform throughout the median eminence.

\section{Two Months After Ovariectomy}

At two months after ovariectomy, the paired immunostained sections again exhibited an ovariectomy-induced reduction in demonstrable GnRH in all sampled regions of the median eminence (Figs. 17-22). The pattern of response in each region was essentially the same as that observed at one month.

Image analysis of these sections (Fig. 23) indicated for each sampled region that ovariectomy resulted in a significant decrease in both specimen area covered by reaction product and average unit density of immunostaining for GnRH. As at one month, the decrease in average density was uniform throughout the median eminence, while the reduction in area varied, with the greatest absolute decrease in area occurring in the infundibular region.

\section{Radioimmunoassay}

The RIA data (Fig. 24) showed that the GnRH content of the basal hypothalamus was not significantly different from control values at two weeks after ovariectomy. At both one and two months, however, there was a significant decrease $(\mathbf{p}<0.005)$ in the tissue content of this hormone in the ovariec- 

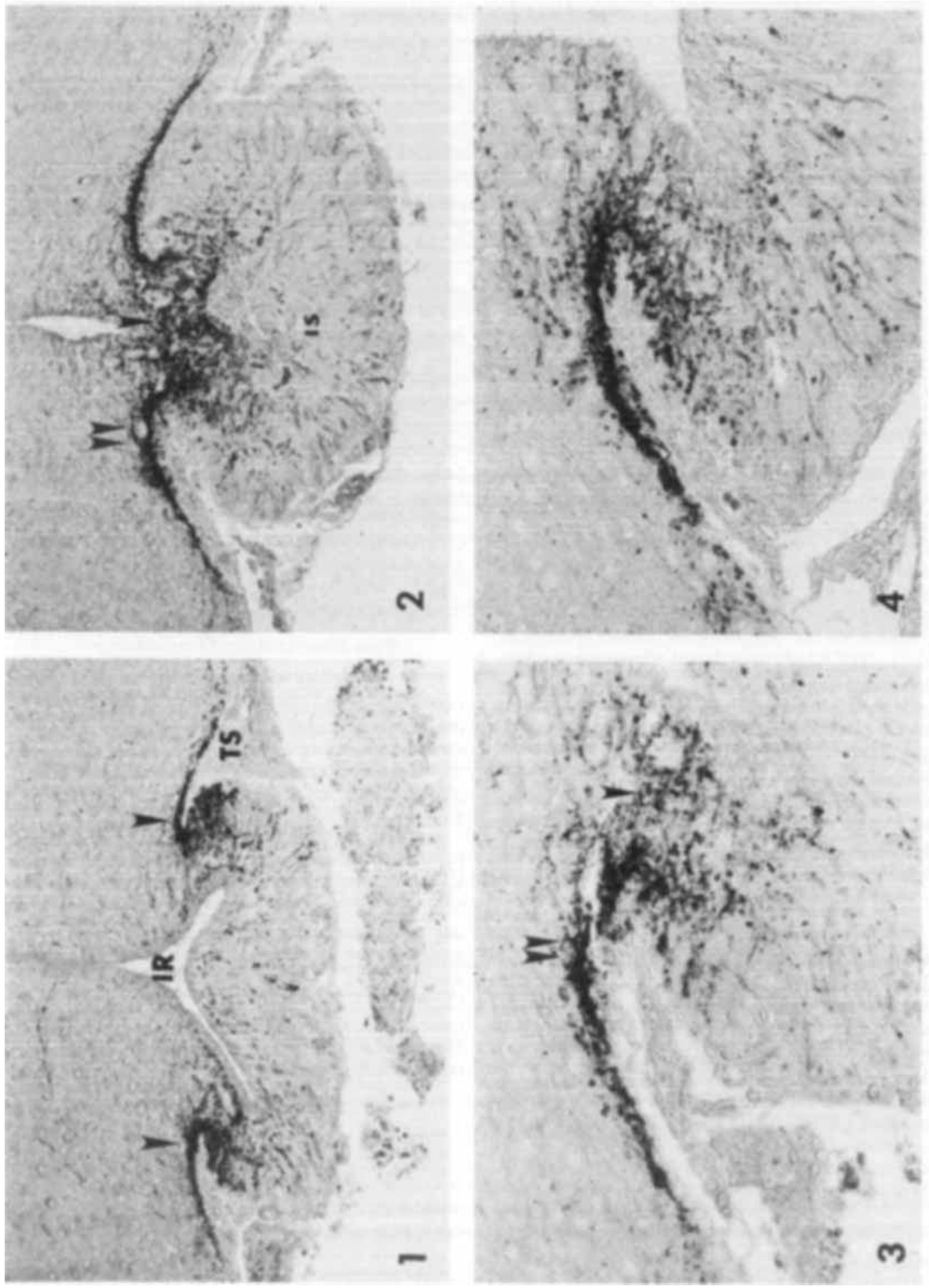

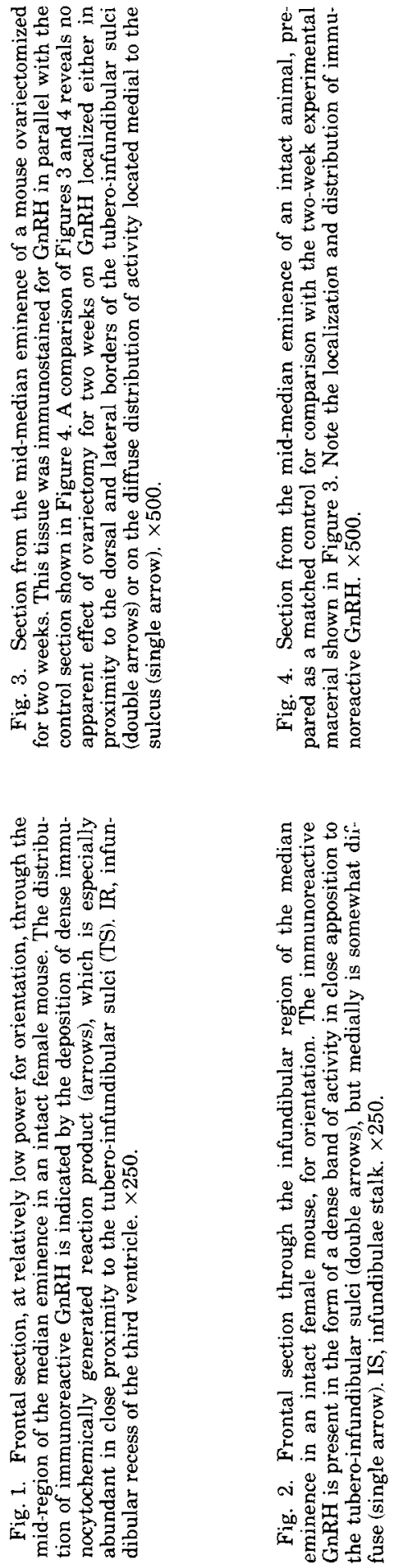

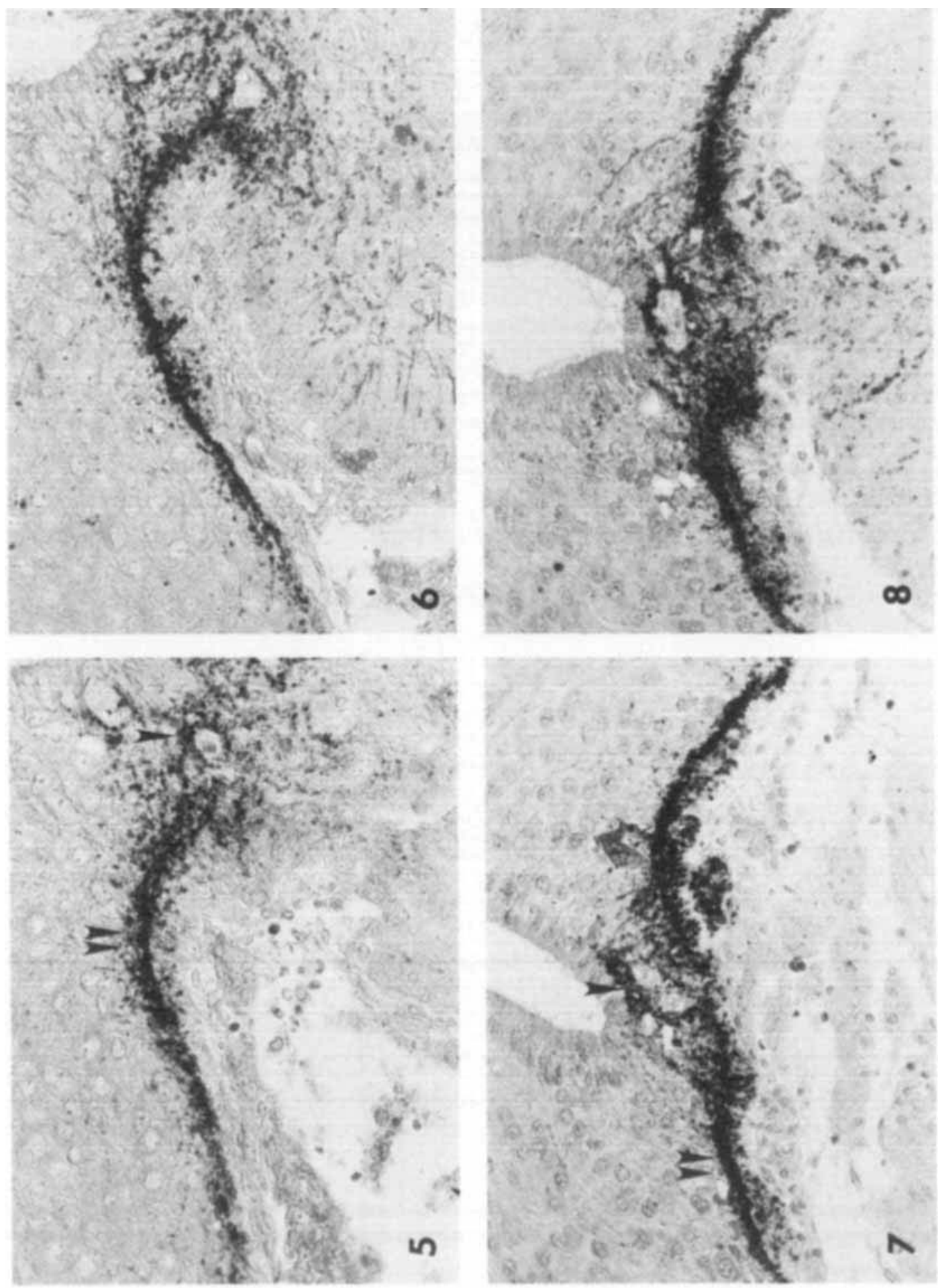

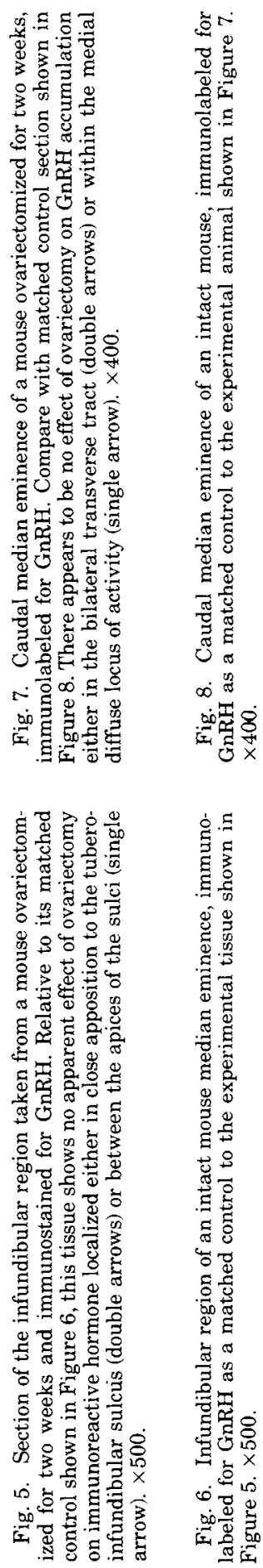


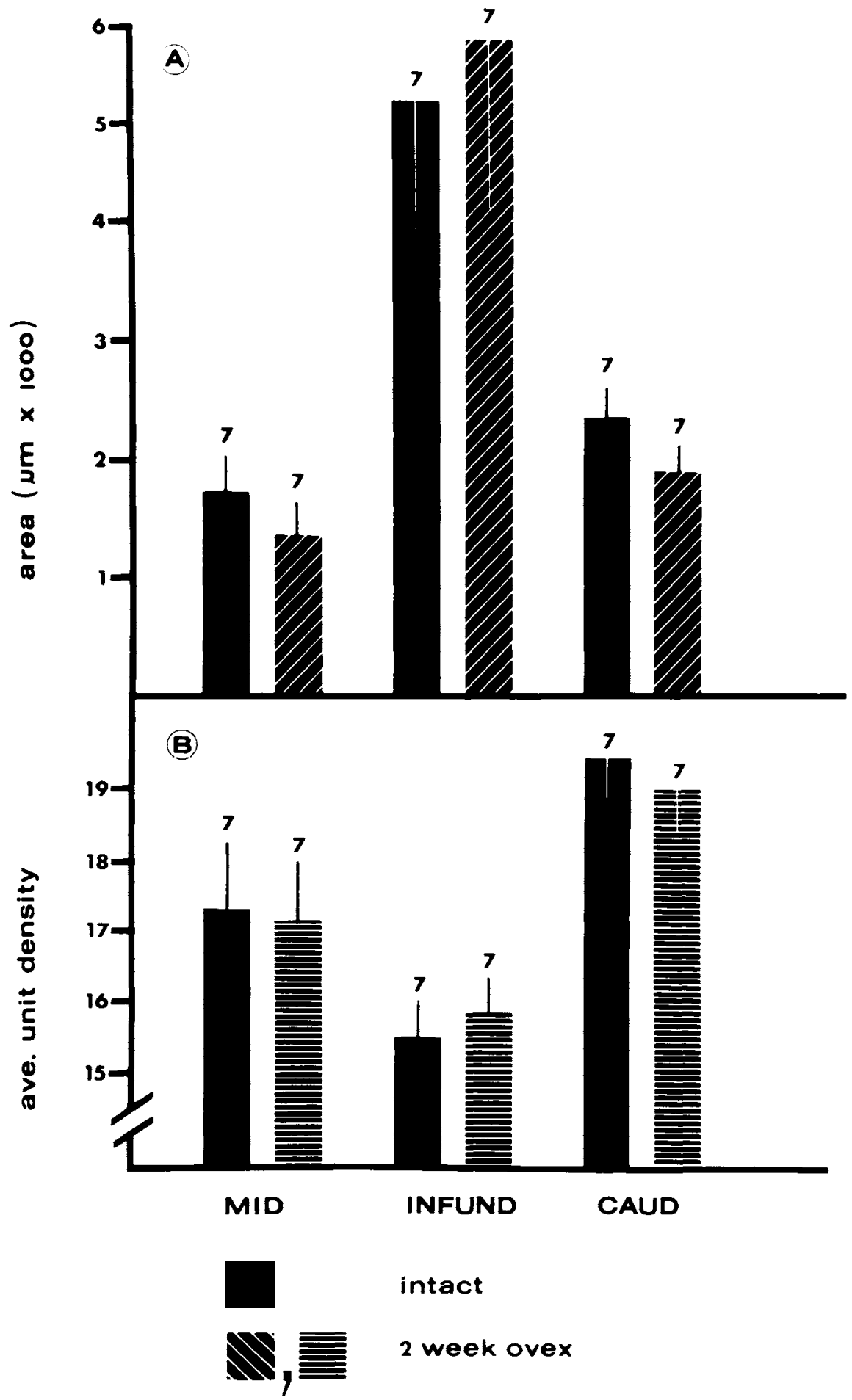

Fig. 9. Effect of ovariectomy for two weeks on the area of distribution (A) and average density (B) of immunolabeled GnRH in three regions of the median eminence in the female mouse, as analyzed quantitatively with the Quantimet 720 Image Analyzer. In all of the

graphs, solid bars indicate mean values for control animals; while the hatched bars indicate corresponding mean values from ovariectomized animals. Vertical lines indicate SEM, and numbers above bars are the number of animals per bar. 
tomized mice, compared to intact controls. The magnitude of this response did not differ significantly between one and two months.

\section{DISCUSSION}

The quantitative data described in the present study, obtained with both RIA and quantitative immunocytochemistry, provide solid evidence that ovariectomy after one or more months in the mouse results in a significant decrease in the immunoreactive $\mathrm{GnRH}$ content of the basal hypothalamus, while at two weeks after ovariectomy the content is not significantly changed. These quantitative findings confirm and extend the previous qualitative observations of Briski (1979) and of Gross (1980). The image analyses carried out on immunocytochemical preparations in the present study have shown that the decrease in demonstrable $\mathrm{GnRH}$ after one or two months of ovariectomy includes a significant reduction in both the area of neural tissue covered by reaction product and the average unit density of immunostaining.

The present findings may be compared with those obtained by Gross (1980), who studied the effect of gonadectomy and steroid hormone replacement therapy on immunolabeled hypothalamic GnRH in male and female rats and mice. In that paper, utilizing immunocytochemistry analyzed by visual comparison (without correlated radioimmunoassay), it was concluded for the mouse that after two weeks of gonadectomy there was no detectable change in immunoreactive $\mathrm{GnRH}$ in the median eminence, but that a reduction was seen at five weeks. No mention was made of variability within each group nor of problems involved in making visual comparisons. We found a certain variability from animal to animal in the same group, which we believe may reflect normal variations in $\mathrm{GnRH}$ content of the mouse median eminence. These minor fluctuations caused us to seek a more quantitative evaluation that could be assessed statistically. A decrease in $\mathrm{GnRH}$ immunoactivity is shown in that paper at five weeks, but it is only illustrated for the mouse at five weeks of orchidectomy; and the visual comparisons used in that study do not allow a firm conclusion as to whether the difference is mainly in amount or whether there is also a difference in the area of distribution. Although Gross (1980) concluded that after two weeks ovariectomy in the mouse did not give rise to appreciable reduction in demonstrable hypothalamic $\mathrm{GnRH}$, the figures in his paper show that appears to be a more concentrated and localized $\mathrm{GnRH}$ immunoreactivity in the control (his Figure 4a) than in the two-week experimental (his Figure 5b). This underscores the variability that may be present in such preparations and the problems involved in detailed visual comparisons. Thus, while we do not question the specificity of the immunocytochemical procedure used by Gross (1976, 1980 ) to demonstrate $\mathrm{GnRH}$, we have felt the need for more objective and quantitative means of evaluating immunocytochemical preparations, which has been one of the goals of the present study.

Quantitative image analysis of the immunocytochemical staining for $\mathrm{GnRH}$ in mice ovariectomized for one or two months revealed that the decrease observed in each region of the median eminence was characterized by a significant reduction in both the area of neural tissue covered by reaction product and the average unit density of immunostaining. The decrease in area suggests that ovariectomy results in the total depletion of immunoreactive hormone from some axons, or at least reduction of their hormone content below the limit of sensitivity of the immunocytochemical techniques used in the present study. This loss of immunoreactivity could indicate either a massive release of hormone from these axons or a further decrease in already low hormone stores. Furthermore, the decrease in unit density of reaction deposit within the residual detected area in the ovariectomized animals indicates that the net $\mathrm{GnRH}$ immunoreactivity within axons present in this total area is reduced significantly below control values. There are several possible explanations for this reduction in unit density, including a variable decrease in hormone in detected $\mathrm{GnRH}$ axons or a depletion of hormone from some axons present within the detected area. It is possible that both of these events contribute to the overall reduction in unit density of demonstrable hormone.

The overall decrease in tissue hormone content after one or more months of ovariectomy most likely reflects an enhanced secretion of GnRH by the mouse hypothalamus. To date, there have been no studies in the mouse or any other species establishing a direct correlation of changes in the hypothalamic content of immunoreactive $\mathrm{GnRH}$ are directly correlated with changes in the net output of this hormone into the portal plasma. However, the hypothesis that a de crease in hypothalamic GnRH content indi- 

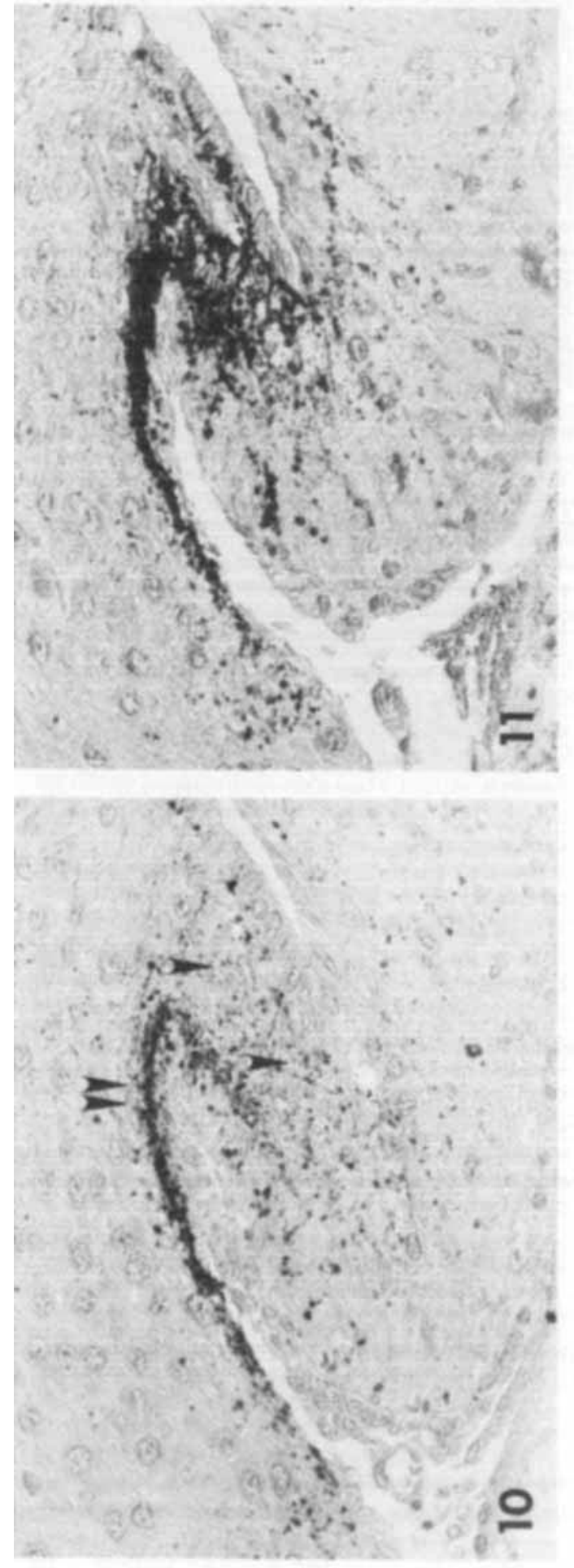
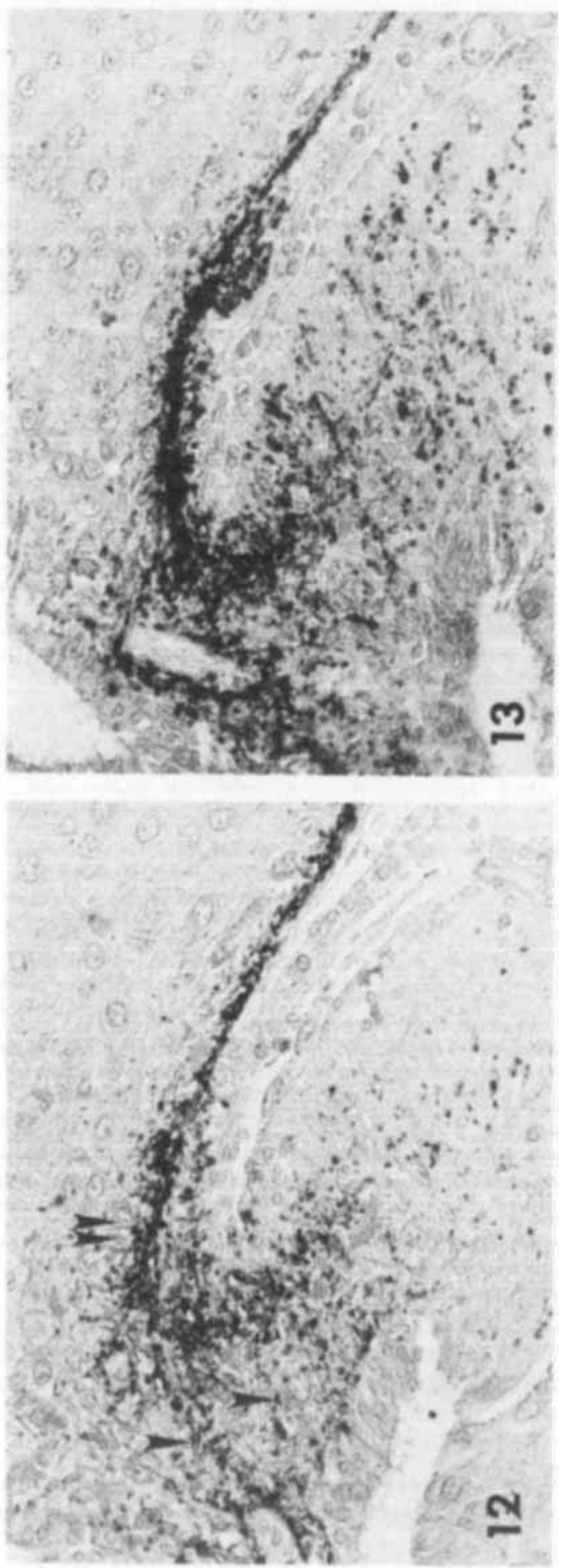

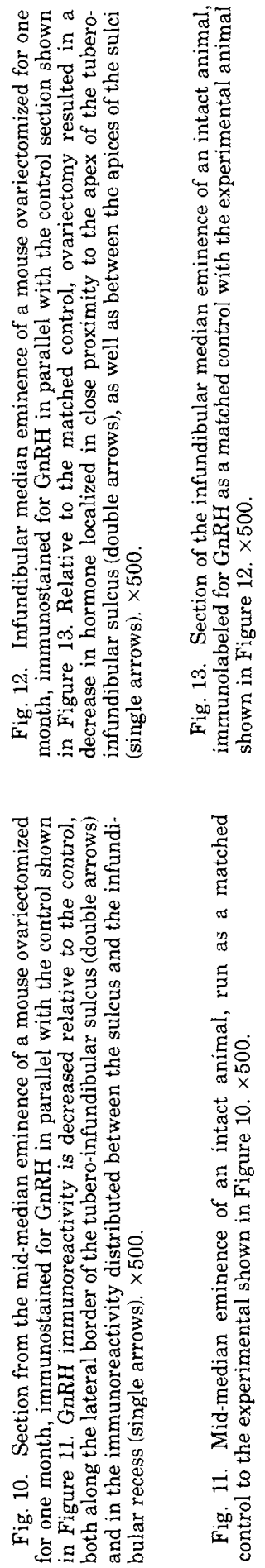

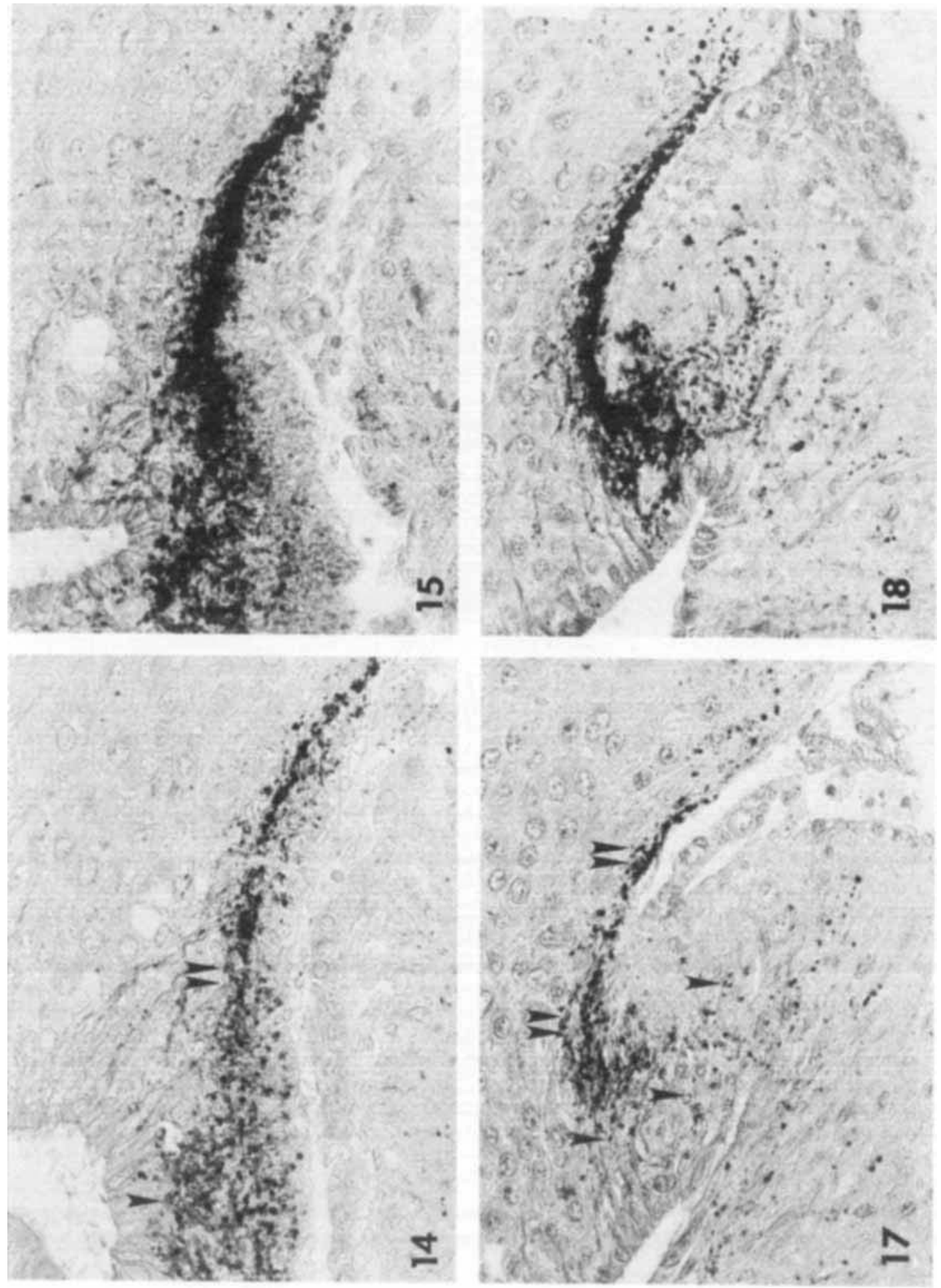

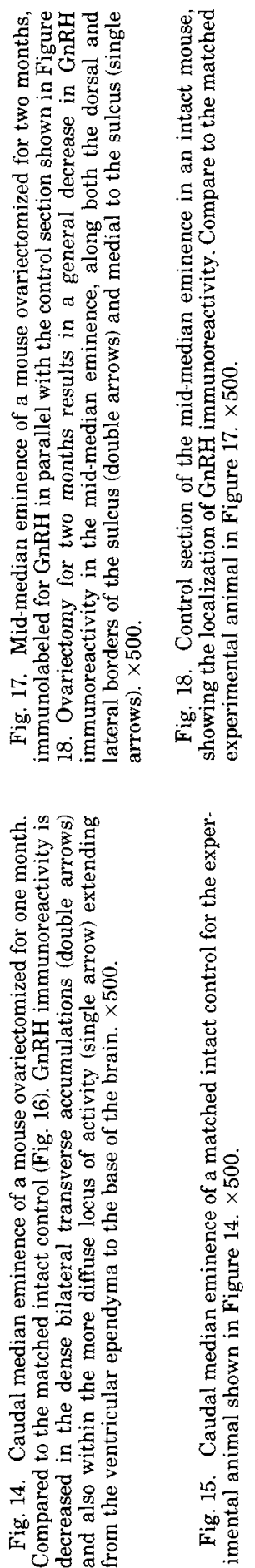


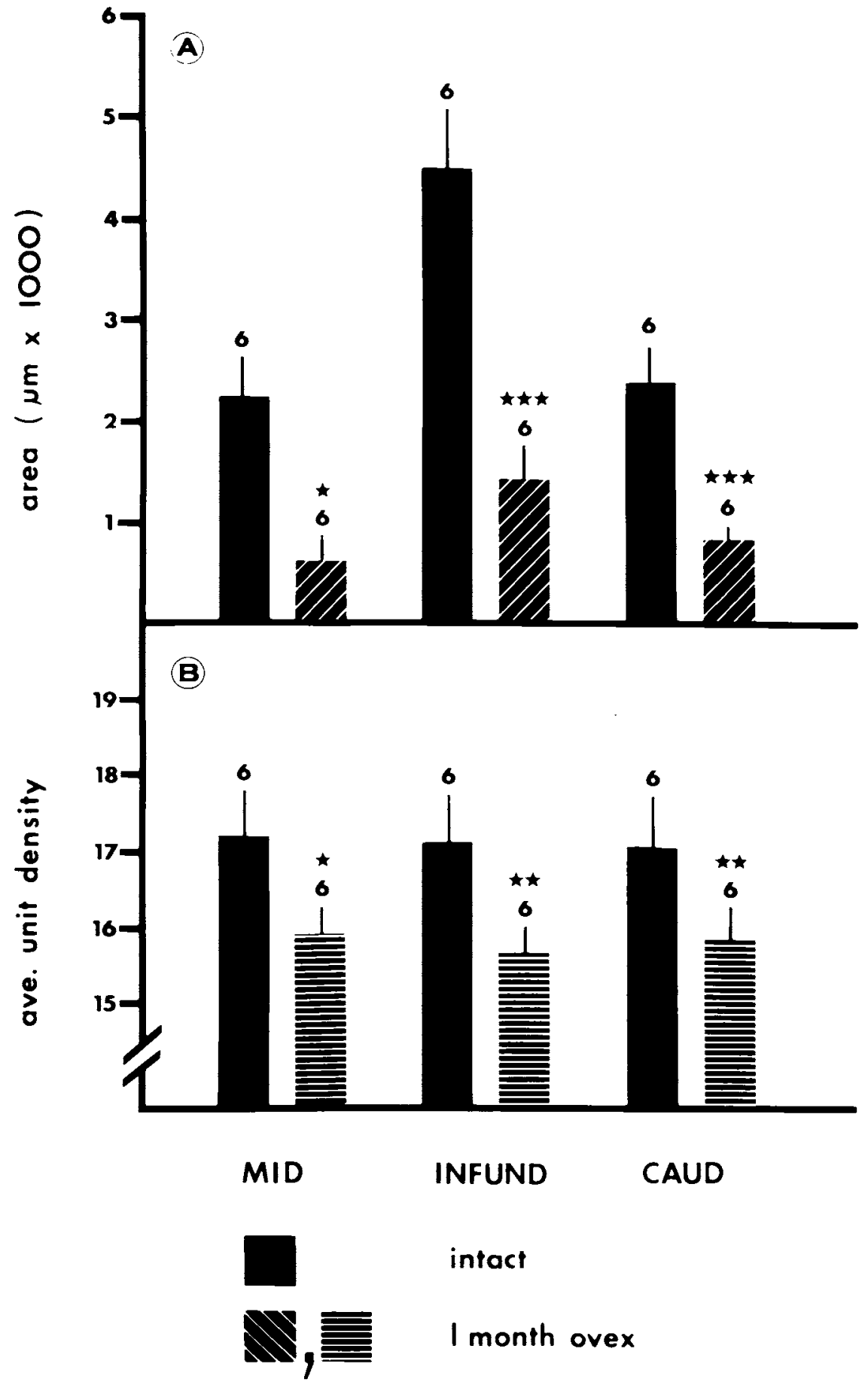

Fig. 16. Effect of ovariectomy for one month on the area of distribution (A) and average density (B) of immunostaining for $\mathrm{GnRH}$ in the mouse median eminence, as analyzed quantitatively with the Quantimet $720 \mathrm{Im}$ -

age Analyzer. $\star$ indicates $\mathrm{P} \leqslant 0.01, \star$ indicates $\mathrm{P} \leqslant$ 0.025 , and $\star \star \star$ indicates $\mathrm{P} \leqslant 0.005$, when the experi mental value is compared to its corresponding control. 
cates an increase in $\mathrm{GnRH}$ neurosecretion is supported indirectly by studies in the gonadectomized rat showing that at the same time points at which hypothalamic GnRH content is decreased (Wheaton and McCann, 1976; Chen et al., 1977; Badger et al., 1978; Kobayashi et al., 1978), there is a detectable increase in both the rate of biosynthesis of hypothalamic GnRH (Moguilevsky et al., 1975; Reichlin, 1976) and the release of this neurohormone into the portal plasma (Ben-Jonathan et al., 1973; Eskay et al., 1977; Sherwood and Fink, 1980). Thus, the present study and others suggest a responsiveness of the mouse hypothalamus to the absence of the gonads, resulting in an increased GnRH neurosecretion, at least in the chronically ovariectomized animal.

The localization of GnRH immunoreactivity in animals ovariectomized for either one or two months revealed a widespread decrease in immunolabeled GnRH throughout the cephalo-caudal extent of the median eminence, similar to previous observations in this species (Briski, 1979; Gross, 1980). The decrease in immunostaining for $\mathrm{GnRH}$ throughout most of the area in which GnRH is localized suggests that in each region, fibers sensitive to a reduction in circulating levels of gonadal steroids are topographically distributed throughout most of the $\mathrm{GnRH}$ fiber system. Such fibers may, however, predominate within the more medial aspects of the $\mathrm{GnRH}$ fiber distribution.

Although the ovariectomy-induced decrease in unit density of immunostaining for $\mathrm{GnRH}$ is uniform throughout the median eminence, the absolute reduction in area covered by deposit, as measured by quantitative image analysis, is not constant, but rather shows a relatively greater decrease in the infundibular region than elsewhere in the median eminence. These data imply that a proportionally greater number of axons in this region lose their content of immunocytochemically detectable hormone in response to ovariectomy, relative to the other regions sampled. Because the average unit density of immunolabeling per unit area is constant throughout the control median eminence, this relatively greater decrease in unit area may reflect a greater absolute decrease in GnRH immunoreactivity. In contrast, Gross (1980) suggested that the greatest decrease occurred in the post-infundibular or caudal region of the mouse median eminence. This discrepancy could be due either to the differ- ent methods utilized in the two studies, or to differences between the two strains of mice used.

The immunocytochemical demonstration of a decrease in intra-axonal GnRH in the median eminence of mice ovariectomized for either one or two months is in agreement with our radioimmunoassay data showing a net decrease in basal hypothalamic GnRH at these time points. It should be kept in mind, however, that intrinsic differences in the two methods preclude the interpretation of the two sets of data as exactly parallel. While the radioimmunoassay data in the present study reflect an ovariectomy-induced change in total $\mathrm{GnRH}$ immunoreactivity within basal hypothalamus, the data obatined with immunocytochemistry indicate the effect of ovariectomy on the population of immunoreactive GnRH molecules demonstrable in the tissue after dehydration and paraffin embedding. Another possible difference between the two sets of data may result from the use of a different antiserum in each study. While both antisera hve been demonstrated to be specific for an amino acid sequence contained within the authentic GnRH decapeptide, only $\mathrm{R} 42$, the antiserum used in the present radioimmunoassay analysis, has been shown to lack affinity for any additional peptides within the basal hypothalamus which may contain this antigenic sequence (Nett et al., 1973), presumably including precursor or prohormonal forms of $\mathrm{GnRH}$ or perhaps biologically different, cross-reactive molecules. Because information of this nature is not presently available for Dermody's \#154 antiserum, the possibility that at least some of the immunolabeled $\mathrm{GnRH}$ activity is actually prohormonal $\mathrm{GnRH}$ or a chemically similar, cross-reactive molecule cannot be eliminated.

In the present study, no significant change in GnRH immunoreactivity was detected with either radioimmunoassay or quantitative immunocytochemistry in mice ovariectomized for two weeks, indicating that the net tissue hormone content is not altered in response to ovariectomy at this time. There are at least two possible interpretations of these findings. First, the results may indicate the lack of a hypothalamic neurosecretory response to ovariectomy at this time point. Alternatively, a $\mathrm{GnRH}$ neurosecretory response to gonadectomy might occur in the absence of a concomitant change in the net intra-axonal GnRH content. It is possible that 

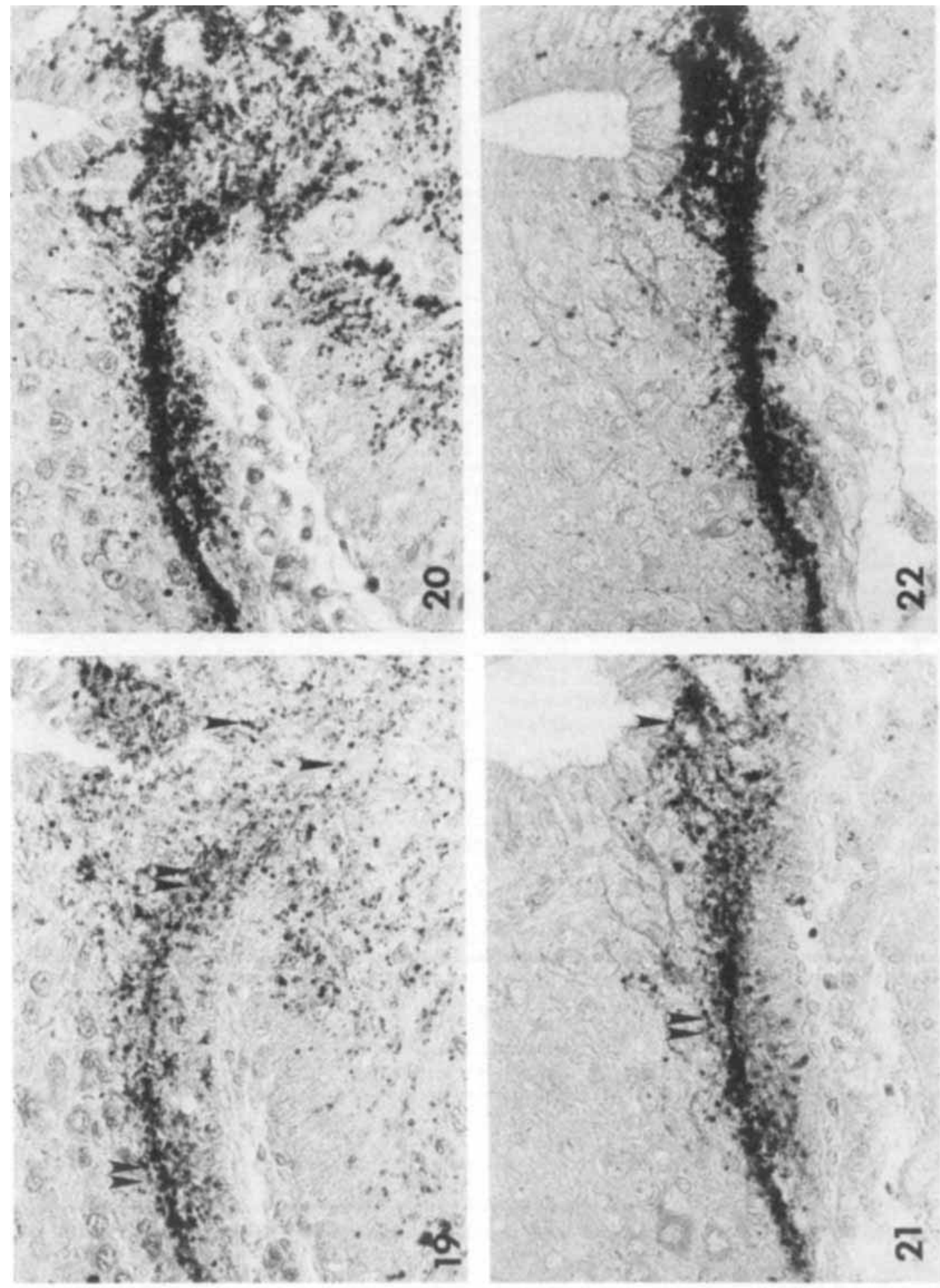


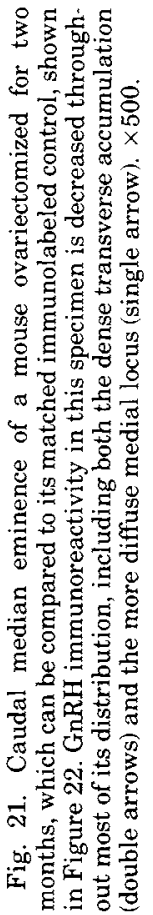

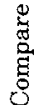

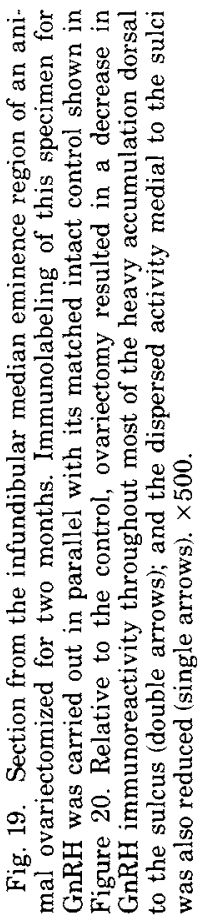




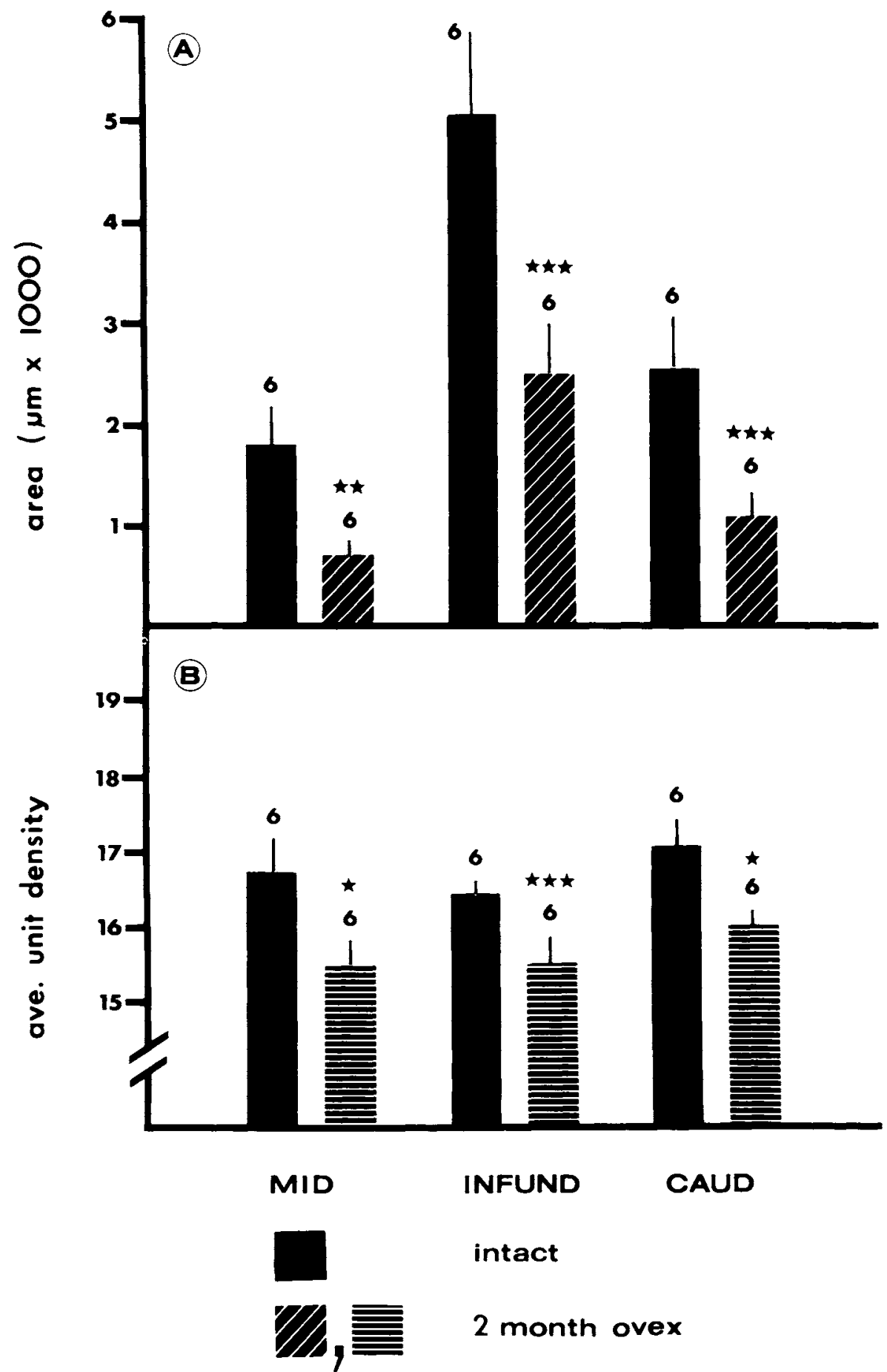

Fig. 23. The effect of ovariectomy after two months on the area of distribution (A) and average density (B) of immunolabeling for $\mathrm{GnRH}$ in the mouse median eminence as analyzed quantitatively with the Quantimet 720

Image Analyzer. $\star$ indicates $\mathrm{P}<0.05, \star$ indicates $\mathrm{P}$ $<0.025$, and $\star \star \star$ indicates $\mathrm{P}<0.005$, when experimental values are compared to the corresponding controls. 


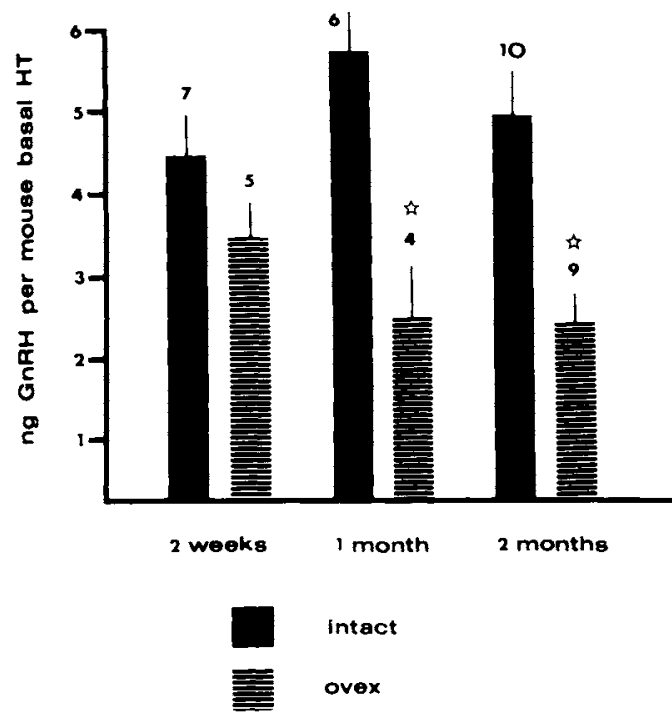

Fig. 24. The effect of ovariectomy on GnRH levels in female mouse basal hypothalamus, as shown by radioimmunoassay. \& indicates $\mathrm{P}<0.005$ when experimental values for $\mathrm{GnRH}$ are compared to the respective intact controls.

changes in the rates of both hormone synthesis and release into the portal plasma could occur without a resultant change in the net amount of hormone present within the axons. One could speculate that the rate of addition of neurosecretory granules to the population contained within the axon and the rate of exocytotic release of granule contents both increase in response to gonadectomy, but that the ratio of these is not changed. Thus, even though the turnover rate of neurosecretory granules would be increased, the total size of the granule population would remain essentially constant.

\section{ACKNOWLEDGMENTS}

Presented in partial fulfilment of requirements for the Ph.D. degree in the Department of Anatomy at the University of Michigan Medical School. Dr. Burton L. Baker framed the original project and guided its development until his death in October, 1978. This research was supported by N.I.H. research grant HD 03159.

\section{LITERATURE CITED}

Araki, S., M. Ferin, E.A. Zimmerman, and R.L. Vande Wiele 1975 Ovarian modulation of immunoreactive gonadotropin releasing hormone $(\mathrm{Gn}-\mathrm{RH})$ in the rat brain: evidence for a differential effect on the anterior and mid-hypothalamus. Endocrinology, 96:644-650.
Badger, T.M., C.E. Wilcox, E.R. Meyer, R.D. Bell, and T.H. Cicero 1978 Simultaneous changes in tissue and serum levels of luteinizing hormone, follicle-stimulating hormone and luteinizing hormone/follicle-stimulating hormone releasing factor after castration. Endocrinology, 102:136-141.

Ben-Jonathan, N., R.S. Mical, and J.C. Porter 1973 Superfusion of hemipituitaries with portal blood. I. LRF secretion in castrated and diestrous rats. Endocrinology, 93:497-503.

Briski, K.P. 1979 Changes in hypothalamic gonadotropin-releasing hormone $(\mathrm{GnRH})$ after ovariectomy in female mice, as demonstrated with immunocytochem. istry. Anat. Rec., 193:491 (abstrt).

Campbell, G.T., and J.A. Ramaley 1978 Immunohistochemistry of hypothalamic GnRH following manipulation of sex steroid levels: evidence that androgens have divergent effects on GnRH stores and serum follicle-stimulating hormone levels. Biol. Reprod., 19:620-627.

Chen, H.T., J. Geneau, and J. Meites 1977 Effects of castration, steroid replacement and hypophysectomy on hypothalamic LHRH and serum LH. Proc. Soc. Exp. Biol. Med., 156:127-131.

Eskay, R.L., R.S. Mical, and J.C. Porter 1977 Relationship between luteinizing hormone releasing hormone concentration in hypophysial portal blood and luteinizing hormone release in intact, castrated and electrochemically-stimulated rats. Endocrinology, 100:263-270.

Gross, D.S. 1976 Distribution of gonadotropin releasing hormone in the mouse brain as revealed by immunocytochemistry. Endocrinology, 98:1408-1417.

Gross, D.S. 1980 Effect of castration and steroid replacement on immunoreactive gonadotropin-releasing hormone in the hypothalamus and preoptic area. Endocrinology, 106:1447-1450.

Kobayashi, R.M., K.H. Lu, R.Y. Moore, and S.S.C. Yen 1978 Regional distribution of hypothalamic luteinizing hormone releasing hormone in proestrous rats: effects of ovariectomy and estrogen replacement. Endocrinology, 102:98-105.

Mogulievsky, J.A., M.A. Enero, B. Szwarcfarb, and D. Dosoretz 1975 Effects of castration and testosterone in vitro on the hypothalamic synthesis of different peptide fractions. J. Endocrinol., 64:405-432.

Monroe, B.G. 1967 A comparative study of the ultrastructure of the median eminence, infundibular stem and neural lobe of the hypophysis of the rat. Z. Zellsjorsch Mikroskop. Anat, 76:405-432.

Nett, T.M., A.M. Akbar, G.O. Niswender, M.T. Hedlund, and W.F. White 1973 A radioimmunoassay for gonadotropin-releasing hormone (GnRH) in serum. J. Clin. Endocrinol., 36:880-885.

Polkowska, J., and M. Jutisz 1979 Local changes in immunoreactive gonadotropin releasing hormone in the rat median eminence during the estrous cycle. Correlation with the pituitary luteinizing hormone. Neuroendocrinology, 28:281-288.

Reichlin, S. 1976 Biosynthesis and degradation of hypothalamic hypophysiotropic factors. In: Subcellular Mechanisms in Reproductive Neuroendocrinology. F. Naftolin, K.J. Ryan, and J. Davies, eds. Elsevier, Amsterdam, pp. 109-127.

Sherwood, N.M., and G. Fink 1980 Effect of ovariec tomy and adrenalectomy on luteinizing hormone-releasing hormone in pituitary stalk blood from female rats. Endocrinology, 106:363-368.

Shin, S.H., and C.J. Howitt 1976 Effect of testosterone on hypothalamus LH-RH content. Neuroendocrinology, 21:165-174. 
Snabes, M.C., R.P. Kelch, and F.J. Karsch 1977 A daily neural signal for luteinizing hormone release in the untreated ovariectomized rat: changes in gonadotropin-releasing hormone content of the preoptic area and hypothalamus throughout the day. Endocrinology, $100: 1521-1526$.

Sternberger, L.A., P.H. Hardy, Jr., J.J. Cuculis, and H.G. Meyer 1970 The unlabeled antibody enzyme method of immunocytochemistry. Preparation and properties of soluble antigen-antibody complex (horseradish peroxidase-antiperoxidase) and its use in identification of spirochetes. J. Histochem. Cytochem., 18:315-333.

Wheaton, J.E. 1979 Regional brain content of luteinizing hormone-releasing hormone in sheep during the estrous cycle, seasonal anestrus, and after ovariec tomy. Endocrinology, 104:839-844.

Wheaton, J.E., and S.M. McCann 1976 Luteinizing hormone-releasing hormone in peripheral plasma and hypothalamus of normal and ovariectomized rats. Neuroendocrinology, 20:296-310.

Whitten, W.K. 1966 Pheromones and mammalian reproduction. In: Advances in Reproductive Physiology, Vol. 1. A. McLaren, ed. Academic Press, New York, pp. 155-177.

Whitten, W.K., and A.K. Champlin 1973 The role of olfaction in mammalian reproduction. In: Handbook of Physiology, Section 7, Vol. 2. R.O. Greep, ed. Waverly Press, Baltimore, pp. 109-123. 